\title{
Characterization of wheat genotypes for stay green and physiological traits by principal component analysis under drought condition
}

\author{
R. SHIVRAMAKRISHNAN*, R. VINOTH ${ }^{1}$, AJAY ARORA, G.P. SINGH ${ }^{2}$, B. KUMAR ${ }^{3}$ AND V.P. SINGH \\ Division of Plant Physiology, Indian Agricultural Research Institute, NEW DELHI, INDIA \\ (Email : shivram.krishnan2008@gmail.com)
}

\begin{abstract}
An experiment was conducted to examine the magnitude of genetic diversity and characters contributing to genetic diversity among 35 core elite wheat germplasm from INDIA and CIMMYT under water deficit condition. Principal components (PC) analysis showed that three components explained 67.73 per cent of the total variation among traits. The first PC contribute 38.8 per cent, second $\mathrm{PC}$ contribute 17.17 per cent and third $\mathrm{PC}$ contribute 11.66 per cent of total variation between traits. The first PC was more related to LSR, DSI, SCMR, RWC, ear weight per plant, harvest index and grain yield. The second PC was more related to plant height, LSR, tillers per plant, biological yield, thousand kernel weight and RWC. Therefore, selection based on first component is helpful for a good hybridization breeding program. Genetic divergence was carried out and grouped genotypes into six genetically distinct clusters. Cluster II genotypes viz., CHIRYA7, HW2041 and PBW502 shows superiority for functional stay green trait by exhibiting low cluster mean for leaf and DSI, and high cluster mean for SCMR, photosynthetic rate, RWC, tillers per plant, ear weight, 1000 kernel weight, biological yield, harvest Index, grain yield per plant and in contrast Cluster IV genotypes are non-stay green and drought susceptible by exhibiting high cluster mean for LSR and DSI. A three dimensional (3D Plot) depicts maximum genetic divergence between HW2041 and CBW38 and CHIRYA7 and HW2033. Stay green trait and all yield attributing traits except plant height can be improved by intermating HW2041 with CBW38 and CHIRYA7 with HW2033 genotypes which result in a highly heterotic hybrid for these traits under water deficit stress in wheat.
\end{abstract}

Key Words : Principal component analysis, Genetic diversity, Leaf senescence rate, Wheat, Drought

View Point Article : Shivramakrishnan, R., Vinoth, R., Arora, Ajay, Singh, G.P., Kumar, B. and Singh, V.P. (2016). Characterization of wheat genotypes for stay green and physiological traits by principal component analysis under drought condition. Internat. J. agric. Sci., 12 (2) : 245251, DOI:10.15740/HAS/IJAS/12.2/245-251.

Article History : Received : 01.02.2016; Revised : 03.03.2016; Accepted : 24.04.2016

\footnotetext{
* Author for correspondence:

${ }^{1}$ Centre for Plant Breeding and Genetics and Plant Breeding, Tamil Nadu Agricultural University, COIMBATORE (T.N.) INDIA

${ }^{2}$ Division of Genetics, Indian Agricultural Research Institute, NEW DELHI, INDIA

${ }^{3}$ Department of Plant Breeding and Genetics, Rajendra Agricultural University, Pusa, SAMASTIPUR (BIHAR) INDIA
} 